\title{
Prompt Reversal of Airway Obstruction Secondary to Angiotensin Converting Enzyme Inhibitor (ACEI) Induced Angioedema by Ecallantide: A Case Report
}

\author{
John R. Cohn \\ Thomas Jefferson University \\ Cara McDaniel \\ Thomas Jefferson University \\ Nathan Richards \\ Thomas Jefferson University \\ Clement.Au follow this and additional works at: https://jdc.jefferson.edu/pulmcritcaregrandrounds \\ University \\ Part of the Medicine and Health Sciences Commons \\ Michael Raramowhow access to this document benefits you
}

\section{Recommended Citation}

Cohn, John R.; McDaniel, Cara; Richards, Nathan; Au, Clement; and Baram, Michael, "Prompt Reversal of Airway Obstruction Secondary to Angiotensin Converting Enzyme Inhibitor (ACEI) Induced Angioedema by Ecallantide: A Case Report" (2012). Division of Pulmonary and Critical Care Medicine Presentations and Grand Rounds. Presentation 51.

https://jdc.jefferson.edu/pulmcritcaregrandrounds/51

This Article is brought to you for free and open access by the Jefferson Digital Commons. The Jefferson Digital Commons is a service of Thomas Jefferson University's Center for Teaching and Learning (CTL). The Commons is a showcase for Jefferson books and journals, peer-reviewed scholarly publications, unique historical collections from the University archives, and teaching tools. The Jefferson Digital Commons allows researchers and interested readers anywhere in the world to learn about and keep up to date with Jefferson scholarship. This article has been accepted for inclusion in Division of Pulmonary and Critical Care Medicine Presentations and Grand Rounds by an authorized administrator of the Jefferson Digital Commons. For more information, please contact:

JeffersonDigitalCommons@jefferson.edu. 


\section{Prompt Reversal of Airway Obstruction Secondary to Angiotensin Converting Enzyme Inhibitor (ACEI) Induced Angioedema by Ecallantide: A Case Report}

J.R. Cohn, C. McDaniel, N. Richards, C. Au, M. Baram

Thomas Jefferson University and Hospitals, Philadelphia, PA 19107

\section{INTRODUCTION}

- Fatal airway obstruction from ACEI angioedema has been described but effective therapy has not been established. Intubation is a kallikrein pathway blocker and may offer benefit in reversing ACEI induced angioedema. sometimes required for progressive airway compromise. Ecallantide is

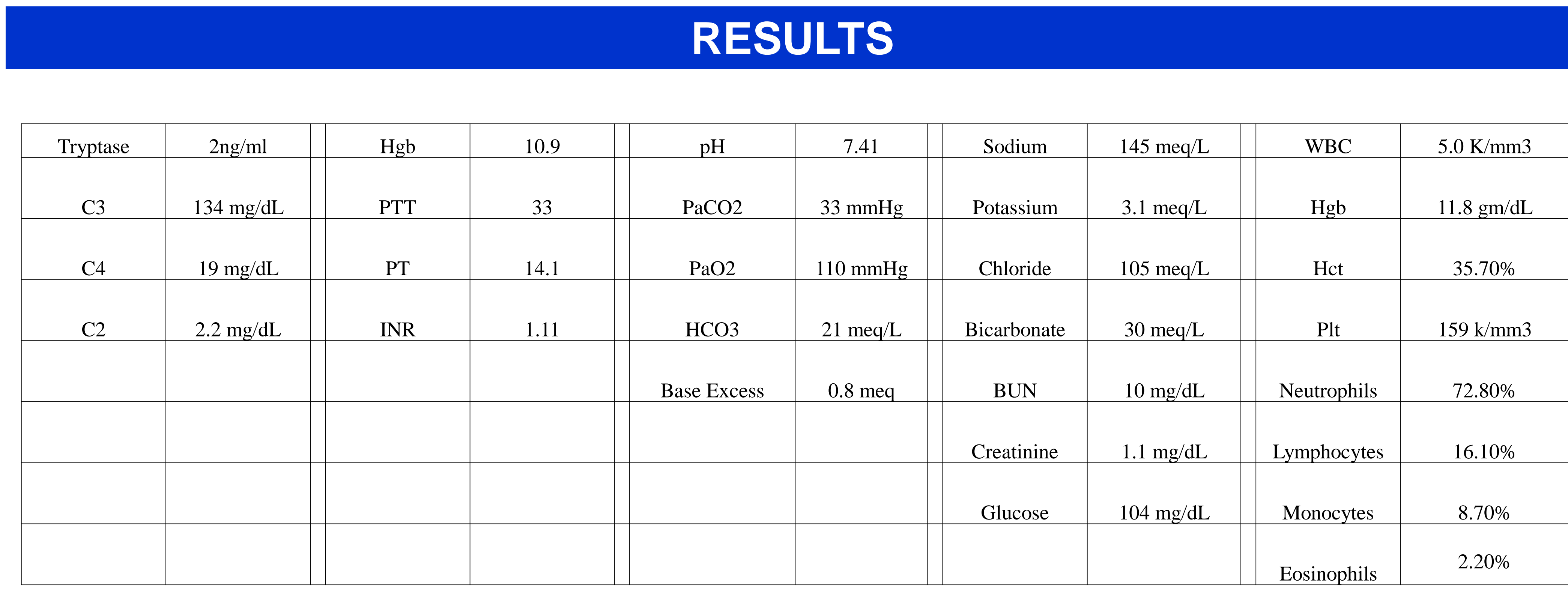

\section{CLINICAL COURSE AND OUTCOME}

- Patient improved over the day and self-extubated prior to 1800 hours. He had no dysphagia or difficulty with respiration and was discharged the next morning.

A 54 year old African-American male with a history of hypertension treated with lisinopril daily, remote cocaine abuse associated myocardial infarction, seizures and prostate cancer, presented with a 2 day history of facial and throa swelling along with dysphagia. He was treated in the emergency department with intravenous methylprednisolone, epinephrine and diphenhydramine. $\mathrm{He}$ was admitted, but angioedema progressed overnight, confirmed by

laryngoscopy. ICU transfer and intubation was undertaken the next morning for airway protection. Tryptase level was $2 \mathrm{ng} / \mathrm{ml}$. C3 and C4 and routine chemistries were normal. Ecallantide $30 \mathrm{mg}$ was administered subcutaneously at 1014 hours.

- Medications: Lisinopril 10mg daily, tamsulosin.

- Family History: No history of angioedema. Parents deceased.

- Social history. Denies current alcohol or recreational drug use.

Review of Systems: Remarkable for hypertension. On disability for back and knee problems.

Physical Exam: Temp 98.8, Respiratory Rate 15, Heart Rate 61, Blood Pressure 130/80, and Oxygen Saturation 99\% on ventilator.

- HEENT- Oral endotracheal tube, limited exam after intubation by Otolaryngology for airway obstruction and desaturation while sleeping.

- Respiratory- Lungs were clear and with good air entry on ventilator.

- Cardiac- Regular heart rate and regular rhythm with no appreciable gallops, murmurs, or rubs.

- Skin- There was no urticaria, other angioedema or rash.
-ACEI angioedema is a recognized complication of ACEI treatment that can occur months to years after starting therapy. The incidence is thought to be $0.1-$ 0.5\% (Warner. Ann Pharmacother 2000; 34: 526). Fatalities from airway obstruction are described (Dean. J Forensic Sci 2001; 46: 1239). Angiotensin converting enzyme is an important enzyme for degradation of bradykinin. Ecallantide selectively and reversibly inhibits plasma kallikrein preventing bradykinin eneration. This case suggests that ecallantide may indeed be effective in reversing ACEI induced angioedema, even in patients requing airway protection.

-This presentation was supported in part by Dyax, Inc

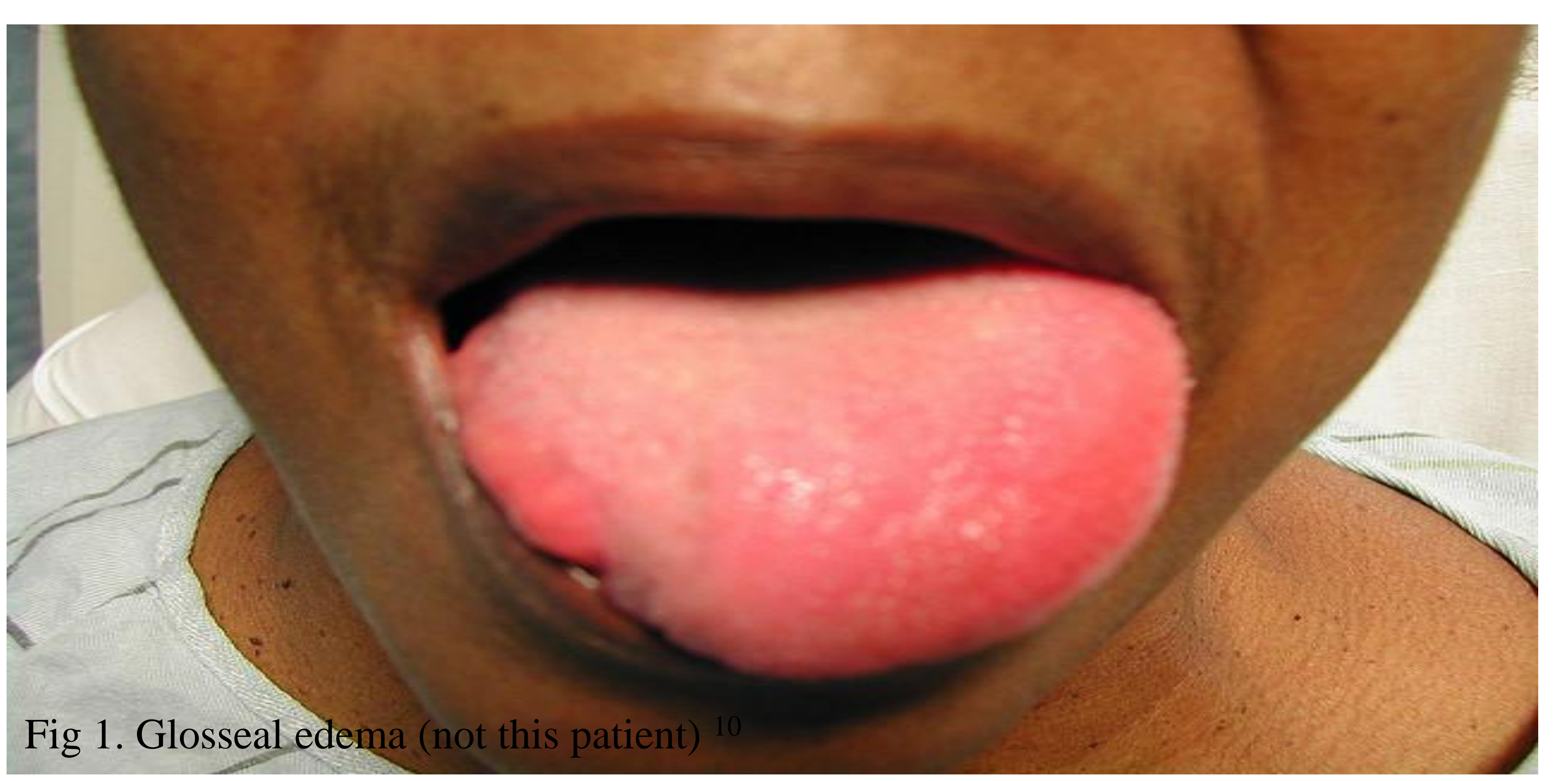

\section{CONCLUSION}

- The mechanism of ACEI angioedema is thought to be from blockade of angiotensin converting enzyme, the major enzyme for degradation of bradykinin.

- Bradykinin and substance P have been linked to the pathogenesis of ACEI induced angioedema. Angiotensin converting enzyme (ACE) is a kinase that breaks down bradykinin ${ }^{4}$. The inhibition of ACE therefore leads to the inhibition of bradykinin catabolism. Bradykinin formation causes vasodilatation and increased vascular permeability by interaction with B-2 receptors. The inhibition of bradykinin catabolism thus leads to angioedema.

- Antihistamines, corticosteroids and epinephrine are ineffective in acute attacks of non-allergic angioedema. The mainstay of treatment currently is airway protection and supportive care. Theoretically, glucocorticoids could lead to a decrease in mucosal swelling. However, there is no demonstrated beneficial effect in patients with angioedema. Inhaled epinephrine may also be effective in laryngeal angioedema ${ }^{8}$.

- Ecallantide is approved treatment of hereditary angioedema. It selectively and reversibly inhibits plasma kallikrein, preventing bradykinin generation. It is theorized that ecallantide can be used to treat other forms of kallikrein dependant angioedema.

- The length of hospitalization for patients with ACEI induced angioedema has ranged from 2 days to 4.8 days 5,9 . Our patient self-extubated a few hours after emergent intubation and was discharged the next day after he remained stable overnight and without distress

- This case suggests that ecallantide may indeed be effective in the cessation of ACEI induced angioedema. Additional randomized studies are underway to confirm these findings

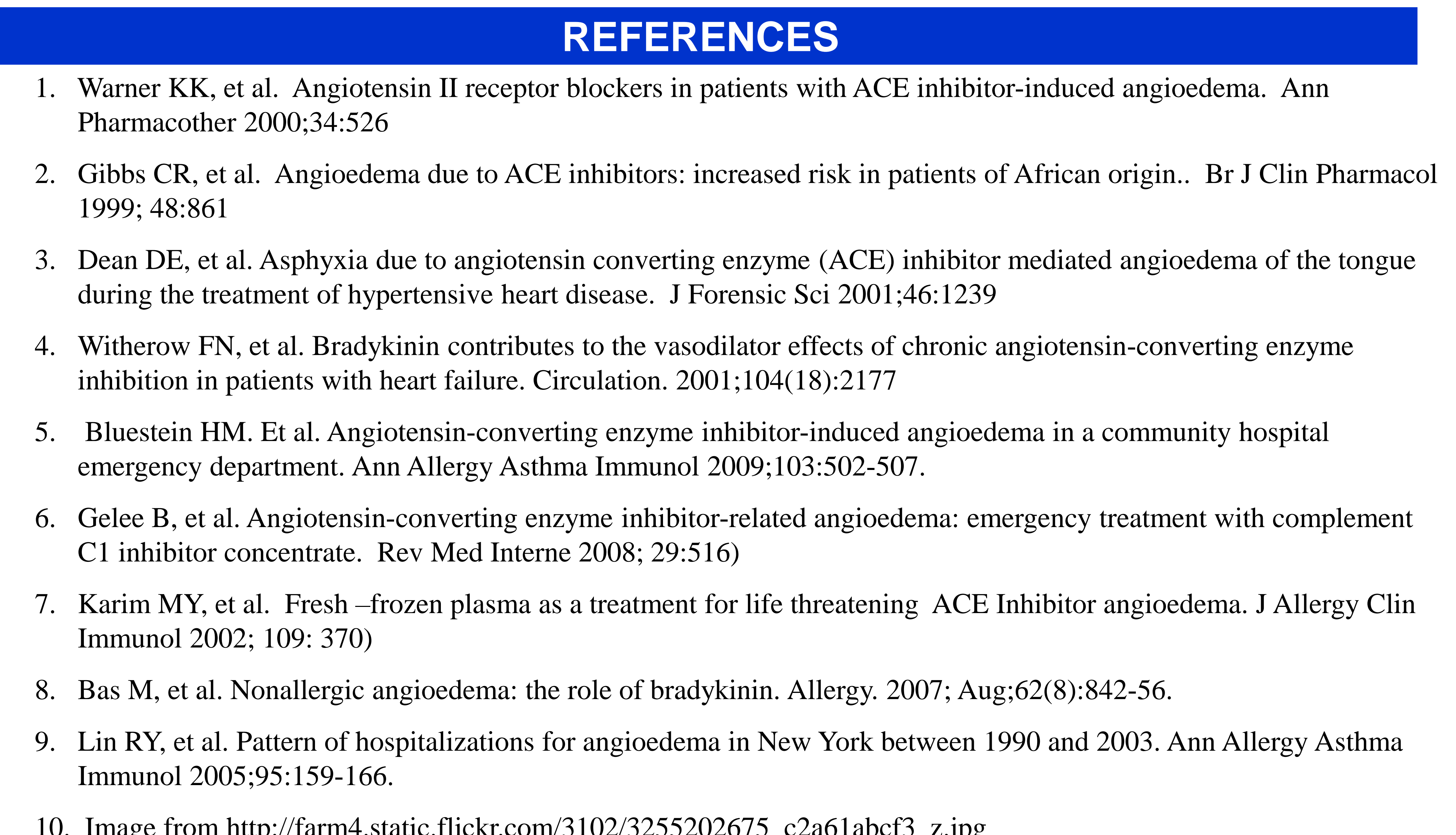

